Research Paper

\title{
Soinolime with Difierent Water Content Causes Difierent Eifects in Two Sevoflurane Inhalational Induction Techniques with Respect to the Output of Compound-A
}

\author{
Shu-jie Liu, Yue Li, Bo Sun, Chang-song Wang, Yu-lei Gong, Yan-mei Zhou and En-you Li ${ }^{\bowtie}$ \\ Department of Anesthesiology, First Affiliated Hospital of Harbin Medical University, Harbin, 150001, China.
}

$\triangle$ Corresponding author: En-you Li, PhD, MD. Department of Anesthesiology, First Affiliated Hospital of Harbin Medical University, No 23 Youzheng Str, Nangang District, Harbin, 150001, China. Tel: +86-13845109928 Fax: +86-0451-82670022 E-mail: enyouli@yahoo.cn.

(c) Ivyspring International Publisher. This is an open-access article distributed under the terms of the Creative Commons License (http://creativecommons.org/ licenses/by-nc-nd/3.0/). Reproduction is permitted for personal, noncommercial use, provided that the article is in whole, unmodified, and properly cited.

Received: 2012.04.03; Accepted: 2012.07.16; Published: 2012.07.25

\begin{abstract}
Objective: During sevoflurane anesthesia with Sofnolime for $\mathrm{CO}_{2}$ absorption, the factors affecting the production of compound $\mathrm{A}$ (a chemical is nepherotoxic) are still not clear. This study is designed to investigate the effects of different fresh gas flow during induction, the vital capacity induction $(\mathrm{VCl})$ vs. the tidal volume breath induction $(\mathrm{TBI})$ on the compound-A production with a fresh Sofnolime or a dehydrated Sofnolime using a simulated lung model.

Method: The experiments were randomly divided into four groups: group one, VClf, vital capacity fresh gas inflow with fresh Sofnolime; group two, TBIf, tidal volume breath fresh gas inflow with fresh Sofnolime; group three, VCld, vital capacity fresh gas inflow with dehydrated Sofnolime, and group four, TBId, tidal volume breath fresh gas inflow with dehydrated Sofnolime. The inspired sevoflurane was maintained at $8 \%$, the concentrations of compound-A were assayed using Gas-spectrum technique, and Sofnolime temperatures were monitored at I-min intervals throughout the experiment.

Results: The mean and maximum concentrations of compound $A$ were significantly higher in the vital capacity group than the tidal volume breath group $(\mathrm{P}<0.0 \mathrm{I})$. At the beginning of anesthesia maintenance, the compound-A concentration in group VClf was $36.28 \pm 6.13 \mathrm{ppm}$, which was significantly higher than the $27.32 \pm 4.21$ ppm observed in group TBIf $(P<0.01)$. However, these values decreased to approximately $2 \mathrm{ppm}$ in the dehydrated Sofnolime groups. Sofnolime temperatures increased rapidly in the dehydrated Sofnolime groups but slowly in the fresh Sofnolime groups.

Conclusion: With fresh Sofnolime, vital capacity induction increased compound-A production in the circuit system compared with tidal volume breath induction. However, with dehydrated Sofnolime, the effects of the two inhalation induction techniques on compound-A output were not significantly different.
\end{abstract}

Key words: anesthesia, inhalation; inhalation, sevoflurane; compound-A; Sofnolime; model lung.

\section{Introduction}

Sevoflurane is the most common choice for inhalational induction agent in children and adult patients for general anesthesia, and also reported to be used in patients with a known difficult airway (1-4) because it exhibits low blood/gas solubility and its non-irritating property (5). However sevoflurane can react with carbon dioxide $\left(\mathrm{CO}_{2}\right)$ absorbents and degraded to compound-A $(6,7)$, which is nephrotoxic (8-10). In a previous study, we demonstrated that sevoflurane (only sevoflurane causes the production 
of compound A) anesthesia, the increase of compound A concentration was more rapid and higher with vital capacity induction (VCI) than with tidal volume breath induction (TBI) when a fresh Sofnolime was used (11). The dryness of $\mathrm{CO}_{2}$ absorbents is an important determinant of sevoflurane degradation, there were studies suggested that the production of compound A is significantly increased when a dehydrated Sofnolime was used (e.g., a neglected fresh gas flush over the night) (12).

The aim of the present study was to investigate the effects of VCI and TBI on the output of compound-A with fresh and dehydrated Sofnolime using a simulation lung model.

\section{Materials and Methods}

To simulate clinical conditions, an artificial lung was connected to an anesthesia machine (Drager Fabius GS, Lubeck, Germany) mounted with an Abbott Calibrated Vaporizer (Abbott Laboratories, North Chicago, IL, USA). A total of $200 \mathrm{ml} . \mathrm{min}^{-1}$ of $\mathrm{CO}_{2}$ was delivered to the artificial lung through a calibrated rotameter. A continuous air sample $200 \mathrm{ml} \cdot \mathrm{min}^{-1}$ was removed from the artificial lung via a Y-piece and fed into a gas analyzer (S/5; Datex-Ohmeda, Helsinki, Finland) for the online analysis. A thermistor probe (DT-300; Intermedical, Tokyo, Japan) was placed in the center of the absorbent canister for continues monitoring the changes of temperature (13). The temperature was monitored over a range of $0.0-100.0^{\circ} \mathrm{C}$.

The experiments were randomly divided into four groups, with 12 replicates for each group. Group VCIf (vital capacity gas inflow with fresh Sofnolime): immediately after the placement of $1,200 \mathrm{~g}$ of fresh Sofnolime into the absorbance canister, the anesthesia circuit was primed with $8 \%$ sevoflurane vapor in oxygen at $6 \mathrm{~L}^{\mathrm{min}}{ }^{-1}$ for $5 \mathrm{~min}$. The anesthetic bag was full, and excess gas was vented through the pop-off valve. Continuous positive airway pressure (15 $\mathrm{cmH} 2 \mathrm{O}$ ) was applied by partially closing the adjustable pressure-limiting valve for $10 \mathrm{~s}$ to simulate vital capacity breathing. Then, switch to mechanical ventilation with a respiratory frequency of $12 \mathrm{bpm}$ and a tidal volume of $500 \mathrm{ml}$ for $2 \mathrm{~min}$ and $50 \mathrm{~s}$. At this point the mechanical ventilation was stopped, as well as the fresh gas flow (FGF) and dial of sevoflurane were turned off for $1 \mathrm{~min}$ to simulate the time required for endotracheal tube insertion. The FGF was adjusted back to 1 L.min ${ }^{-1}$, i.e., the beginning of anesthesia maintenance. Group VCId (vital capacity gas inflow with dehydrated Sofnolime) was following the same procedure as above, except a dehydrated Sofnolime $(1,200 \mathrm{~g}$ fresh Sofnolime dehydrated by dry oxygen flow through at 10 L.min-1 for 66-68 h). Group TBIf (tidal volume breath induction with fresh Sofnolime) was a tidal volume ventilation induction with a fresh Sofnolime. In this group, the circuit system of the anesthetic machine was not primed. After placing the fresh Sofnolime, the mechanical ventilation was carried out to simulate tidal volume breath (the period including a patient's spontaneous respiration and assisted ventilation) for $3 \mathrm{~min}$, the rest of the procedures were identical to those carried out in group VCIf. Group TBId (tidal volume breath with dehydrated Sofnolime), follows the same experimental procedure as described in group TBIf, except that fresh Sofnolime was replaced with dehydrated Sofnolime. Each experiment was repeated for 12 times.

Gas samples for the measurement of compound-A were drawn from the inspiratory limb of the circuit system with a gas-tight syringe automatically (VICI; Baton Rouge, LA, USA) at 1-min interval after sevoflurane dial turned on and at the beginning of the anesthesia maintenance. The Sofnolime temperature, the end-tidal pressure of carbon dioxide $\left(\mathrm{P}_{\mathrm{ETCO}} \mathrm{CO}_{2}\right)$ and the end-tidal concentration of sevoflurane (ETsevo) were recorded at identical time points.

Compound-A was assayed by a gas chromatography (GC) combined with mass-spectrometric detection (QP-2010; Shimadzu, Tokyo, Japan), i.e., GC-MS. The mass spectrum of compound-A is characterized by prominent peaks at $m / z 69,128,161$ and 180 , which were selected as the targeted ions for qualitative purposes. The ion at $\mathrm{m} / \mathrm{z} 128$ was also selected for quantitative purposes. Before each experimental analysis, the GC-MS system was calibrated with a standard calibration gas prepared from the stock solutions of compound-A to obtain a centration-dependent standard curve of eight points. The lowest limit of detection was $0.1 \mathrm{ppm}$.

\section{Statistical analyses}

The results are expressed in mean \pm standard deviation (SD). The variables of compound-A and Sofnolime temperatures were compared between groups using a two-way ANOVA and within groups using one-way ANOVA with a repeated-measure. The statistical software SPSS version 13.0 (SPSS, Chicago, IL, USA) was used for statistical analyses. $\mathrm{P}<0.05$ was considered to be significant.

\section{Results}

ETsevo were not different significantly among all experimental groups at the end of induction. $\mathrm{P}_{\mathrm{ETCO}}$ were in the range between $35 \mathrm{mmHg}$ and 45 $\mathrm{mmHg}$ and did not differ among groups $(\mathrm{P}>0.05)$. 
The canister temperature increased rapidly and reached a maximum of $38.03 \pm 0.95^{\circ} \mathrm{C}$ with the using of dehydrated Sofnolime (absolute water content $<1 \%$ ). However, we found there was virtually no change in temperature when the circle system was primed and only minor increases during induction with the fresh Sofnolime. The Sofnolime temperature before anesthesia induction and the maximum temperature are shown in Table 1.

At the beginning of induction, the compound-A concentration in TBIf and TBId groups were zero but was approximately $4 \mathrm{ppm}$ in VCIf group and $10 \mathrm{ppm}$ in VCId group $(\mathrm{P}<0.01)$. The concentration of compound-A changed following the use of fresh or dehydrated Sofnolime which are shown separately in Figure 1 and Figure 2, respectively. The mean and maximum concentrations of compound-A during the vital capacity inflow flush was significantly higher than the tidal volume breath inflow experiments $(\mathrm{P}<0.01$, Table 2).

At the beginning of anesthesia maintenance, the compound-A production in VCIf group was $36.28 \pm 6.13 \mathrm{ppm}$, which was significantly higher than TBIf group (27.32 $\pm 4.21 \mathrm{ppm}, \mathrm{P}<0.01$, Table 2). However, the compound-A concentration decreased to approximately $2 \mathrm{ppm}$ in the dehydrated Sofnolime groups. There was no significant difference between VCId and TBId groups $(\mathrm{P}>0.05)$ in compound-A production throughout all experimental sampling points.
Table I. Temperatures of Sofnolime and end-tidal sevoflurane concentration.

\begin{tabular}{lllll}
\hline Group & TBIf & VCIf & TBId & VCId \\
\hline Tinitial $\left({ }^{\circ} \mathrm{C}\right)$ & $28.46 \pm 0.51$ & $28.43 \pm 0.33$ & $28.38 \pm 0.91$ & $28.65 \pm 0.45$ \\
Tmax $\left({ }^{\circ} \mathrm{C}\right)$ & $30.25 \pm 1.08$ & $29.18 \pm 0.39^{*}$ & $33.53 \pm 1.2^{*} \dagger$ & $38.03 \pm 0.95$ \\
Etsevo І3 $(\%)$ & $8.13 \pm 0.19$ & $8.18 \pm 0.09^{*}$ & $7.19 \pm 0.21 \dagger$ & $7.26 \pm 0.22$ \\
$\begin{array}{l}\text { Etsevo м0 } \\
(\%)\end{array}$ & $8.06 \pm 0.23$ & $8.09 \pm 0.15^{*}$ & $6.85 \pm 0.37 \dagger$ & $6.81 \pm 0.45$ \\
\hline
\end{tabular}

Data are the mean $\pm S D, n=12$ for all values; Tinitial : temperature of Sofnolime before experiments; Tmax : maximum temperature of Sofnolime during induction; Etsevo is : end-tidal sevoflurane concentration at the end of induction; Etsevo мо: end-tidal sevoflurane concentration at the beginning of anesthesia maintenance.

*significantly different from the VCId group $(\mathrm{P}<0.01)$; †significantly different from the TBIf group $(\mathrm{P}<0.01)$.

Table 2. Compound-A concentrations in fresh- or dehydrated-Sofnolime groups.

\begin{tabular}{lllll}
\hline Group & TBIf & VCIf & TBId & VCId \\
\hline CA I $_{0}(\mathrm{ppm})$ & 0 & $3.82 \pm 0.36^{*}$ & 0 & $9.95 \pm 2.39$ \\
CAmax (ppm) & $5.22 \pm 1.37$ & $6.82 \pm 0.59^{*} \dagger$ & $11.34 \pm 3.14^{*} \dagger$ & $13.85 \pm 2.45$ \\
CAmean(ppm) & $3.98 \pm 1.31$ & $6.05 \pm 0.58^{*} \dagger$ & $9.26 \pm 2.85^{*} \dagger$ & $12.67 \pm 2.08$ \\
CA M $_{0}(\mathrm{ppm})$ & $27.32 \pm 4.21$ & $36.28 \pm 6.13^{*} \dagger$ & $2.45 \pm 0.84 \dagger$ & $2.15 \pm 0.93$ \\
\hline
\end{tabular}

Data are the mean $\pm \mathrm{SD}, \mathrm{n}=12$ for all values; $\mathrm{CA} \mathrm{I}_{0}$ : compound-A concentration at the beginning of induction; CAmax : maximum concentration of compound-A during induction; CAmean : mean concentration of compound-A during induction; $\mathrm{CA} \mathrm{M}_{0}$ : compound-A concentration at the beginning of anesthesia maintenance; *significantly different from the VCId group $(\mathrm{P}<0.01)$; † significantly different from the TBIf group $(\mathrm{P}<0.01)$.

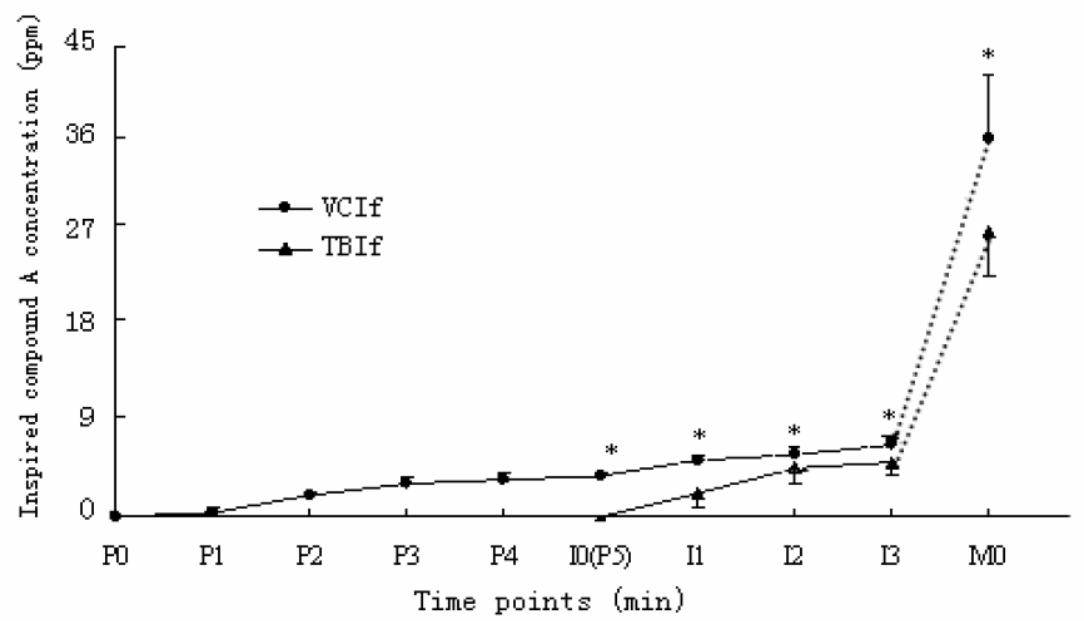

Figure I. Inspired compound-A concentration changes after administration of sevoflurane in fresh-Sofnolime groups. VClf: vital capacity induction with fresh Sofnolime; TBIf: tidal breathing induction with fresh Sofnolime; P0-P5: the time points during priming of the anesthesia circuit in the vital capacity induction group; 10-13: time points during induction; M0: beginning of anesthesia maintenance at which fresh gas flow was adjusted from 6 L. in $^{-1}$ to I L.min ${ }^{-1}$; intervals of time points are I min. $* P<0.05$ compared with the same time point in the TBIf group. 


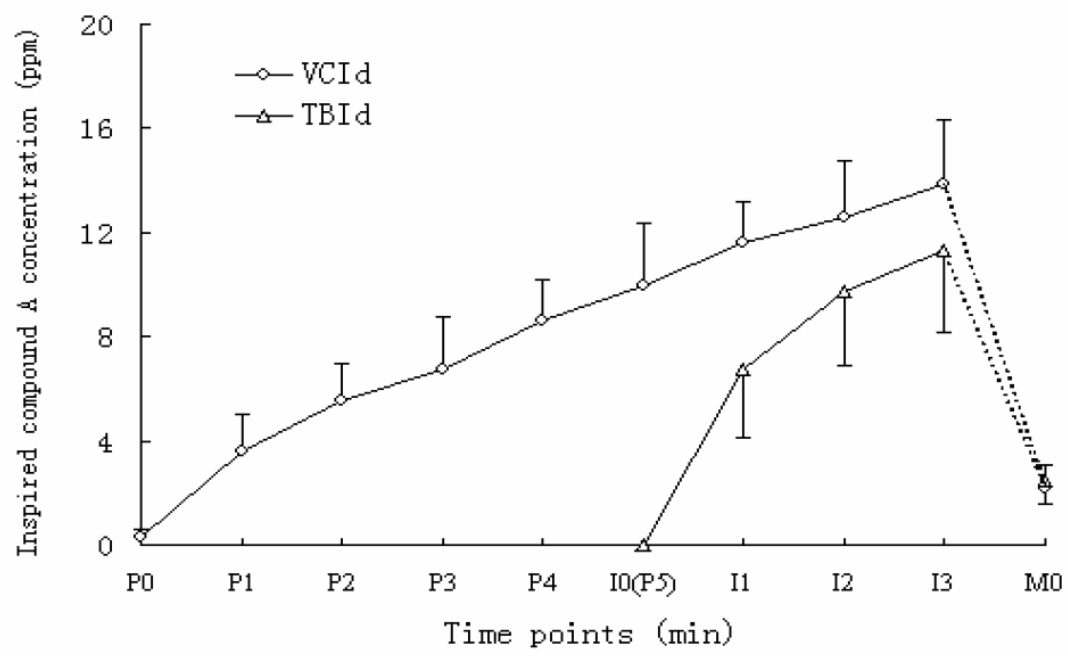

Figure 2. Inspired compound-A concentration changes after administration of sevoflurane in dehydrated-Sofnolime groups. VCld: vital capacity induction with dehydrated Sofnolime; TBId: tidal breathing induction with dehydrated Sofnolime; P0-P5: time points during priming of the anesthesia circuit in vital capacity induction groups; 10-13: time points during induction; M0: beginning of anesthesia maintenance at which fresh gas flow was adjusted from 6 L.min ${ }^{-1}$ to I L.min ${ }^{-1}$; intervals of time points are I min. * P<0.05 compared with the same time point in the TBld group.

\section{Discussion}

Although several reports have shown that sevoflurane may have the property being cardioprotective (14-16), sevoflurane reacts with $\mathrm{CO}_{2}$ absorbents resulting in the generation of compound-A, which has been implicated being renal toxicity in rats at 150-348 ppm-h (8-10) and in human at 320 ppm-h (17). Sevoflurane has been used widely as inhalation induction agent for pediatric and adults anesthesia (1-3), in which requiring a high fresh gas flow to be used to rapidly increase the circuit anesthetic concentration. Compound-A production during induction may be dependent on the rate of fresh gas flow and the concentration of sevoflurane used. Different inhalation induction techniques can result in different compound-A outputs. In our previous clinical study, we found that using vital capacity induction increased the production of compound-A significantly higher than vital volume breath induction with the using of fresh Sofnolime (11).

The concentrations of compound-A have been shown to inversely correlate with the water content of $\mathrm{CO}_{2}$ absorbents (12), implying that the compound-A production may be higher with the using of dehydrated Sofnolime than fresh Sofnolime. One study showed that a simulated inhalation induction with $8 \%$ sevoflurane resulted in a mean compound-A concentration of $183 \mathrm{ppm}$ during the first $10 \mathrm{~min}$ if dry Dragersorb 800 was used (18). Therefore, the present study was designed to use a model lung to simulate clinical conditions by comparing the compound-A production between the application of fresh and dehydrated Sofnolime. Although a model lung was without absorptive or metabolic functions, the results were not affected because concentrations of compound-A detected were from the inspiration limb of the circuit system.

Baker and Smith found that the time from the start of inhalation to the jaw relaxation (the time required to insert a laryngeal mask airway or endotracheal tube) was $154 \pm 63 \mathrm{~s}$ with vital capacity inflow gas and $164 \pm 63 \mathrm{~s}$ with tidal volume breath inflow gas by using $8 \%$ sevoflurane and nitrous oxide and oxygen (ratio 2:1) at $6 \mathrm{~L}^{\mathrm{min}}{ }^{-1}$ for anesthesia induction (19). Hall and co-workers found that the time required using the vital capacity inflow gas to reach the jaw relaxation with $8 \%$ sevoflurane in oxygen at $6 \mathrm{~L} \cdot \mathrm{min}^{-1}$ was $169 \pm 75 \mathrm{~s}$ (though the loss of eyelash reflex was approximately $1 \mathrm{~min}$ ) (20). Therefore, in the present study, the induction time was set at $3 \mathrm{~min}$, and an intubation duration for $1 \mathrm{~min}$ to simulate the clinical conditions.

Previous description of the technique using halothane for rapid inhalation induction indicated (21) a vital capacity breath would causes a breath holding for 30-90 s followed by a regular respiration until the loss of consciousness. Compared to halothane, sevoflurane, which has a smaller blood-gas coefficient, would result in a more rapid increased concentration in alveolar and arterial partial pressure (22). On the basis of this theoretical consideration, the vital capacity breath was set to $10 \mathrm{~s}$ in the present study.

In the present study with a lung model, we 
demonstrated that compared with tidal volume breath, the application of vital capacity inflow gas significantly increased the production of compound-A during sevoflurane inhalation induction with both fresh or dehydrated Sofnolime. This may be because the concentrations of sevoflurane in VCI groups after circuit priming were higher than those in TBI groups at the beginning of induction and higher concentrations of sevoflurane in VCI groups promoted the production of compound A. The present study found that the concentrations of compound-A and the canister temperature with a fresh Sofnolime were lower during induction than those using the dehydrated Sofnolime, suggesting sevoflurane degradation might be inhibited by the presence of water (23).

Interestingly, the compound-A concentrations increased by approximately sixfold in the fresh Sofnolime groups at the beginning of anesthesia maintenance (when the fresh gas flow was adjusted from $6 \mathrm{~L}^{\mathrm{min}}{ }^{-1}$ to $1 \mathrm{~L} \cdot \mathrm{min}^{-1}$ ), which is in agreement with our previous study (11). However, they decreased to approximately $2 \mathrm{ppm}$ in the dehydrated Sofnolime groups at the beginning of anesthesia maintenance. In the fresh Sofnolime groups, the amount of compound-A produced during induction did not appear to have a significant change during intubation, and accumulated in the circuit system. However, the compound-A disappeared during intubation in the groups using dehydrated Sofnolime. The variability of such a finding may be the result of the further degradation sevoflurane to compound-A and further downstream compounds (12). Compared with the fresh Sofnolime, the dehydrated Sofnolime is appreciably different in its capacity to produce or degrade compound A (24). We speculate that in the dehydrated Sofnolime groups, a greater destruction of compound A relative to degradation of sevoflurane. In the chromatograms, we observed two additional peaks behind sevoflurane they were higher and significant. Since we don't have the standard solutions, the identification such could not measure the other degradation products because we could not obtain standard compounds B, C, D or E (25).

Using in vitro lung model, our study clearly demonstrated that inhalational induction with sevoflurane causes a production of compound-A and vital capacity induction with a high flow rate of 6 L. min $^{-1}$ could increase the compound-A production as high as $36 \mathrm{ppm}$. Although there is no clinical report that such a concentration causes acute renal toxicity in clinical anesthesia (26), and the study in normal animals requiring a much higher concentration of compound-A to produce renal damage mediated via the beta-lyase pathway or $\mathrm{N}$-acetylation $(27,28)$, there is no clear answer such concentration remains harmless towards the patients with preexisting renal insufficiency and/or extend exposure time, as well as the changes in physiological condition perioperatively, such as severe anemia and hypotension, etc. Furthermore, the anesthesia provider should be aware that the compound-A production during the induction may be accumulated in the circuit if the fresh gas flow is adjusted to low and under an extended period of such anesthesia. In next, a specific study should be designed to address the effect of a low compound-A concentration on a chronic impaired kidney in animal.

In conclusion, the present study demonstrated that inhalation induction with sevoflurane anesthesia with vital capacity inflow causes an increased production of compound-A with the application of fresh Sofnolime. However, the vital capacity and tidal volume inflow gas rates has no effect on the production of compound-A when dehydrated Sofnolime was used.

\section{Acknowledgments}

The authors thank Dr. Li Peng for his technical assistance with the GC-MS system.

\section{Financial Support}

This project was supported by grants from the National Natural Science Foundation of China (No. 30972839), the Doctoral Fund of Ministry of Education of China (No. 20092307110005) and the Department of Public Health, Heilongiiang, China (No. 2010016).

\section{Competing Interests}

The authors have declared that no competing interest exists.

\section{References}

1. Fritsch N, Nouette-Gaulain K, Bordes M, et al. Target-controlled inhalation induction with sevoflurane in children: a prospective pilot study. Paediat Anaesth.2009; 19: 126-32.

2. Lesage S, Drolet P, Donati F, et al. Low-dose fentanyl-midazolam combination improves sevoflurane induction in adults. Can J Anaesth.2009; 56:733-9.

3. Lin TC, Lu CC, Kuo CK, et al. Single vital-capacity and successive tidal-volume breathing of sevoflurane in induction of anesthesia for tracheal intubation in gynecologic patients. Acta Anaesthesiol Taiwan. 2008; 46: 66-70.

4. Xue FS, Liao X, Li CW, et al. Clinical experience of airway management and tracheal intubation under general anesthesia in patients with scar contracture of the neck. Chin Med J.2008; 121: 989-97.

5. Behne M, Wilke HJ, Harder S. Clinical pharmacokinetics of sevoflurane. Clin Pharmacokinet.1999; 36: 13-26.

6. Liu J, Laster MJ, Eger EI II, et al. Absorption and degradation of sevoflurane and isoflurane in a conventional anesthetic circuit. Anesth Analg 1991; 72: 785-9.

7. Morio M, Fujii K, Satoh N, et al. Reaction of sevoflurane and its degradation products with soda lime. Toxicity of the byproducts. Anesthesiology 1992; 77: 1155-64. 
8. Keller KA, Callan C, Prokocimer P, et al. Inhalation toxicity study of a haloalkene degradant of sevoflurane, compound A (PIFE), in Sprague-Dawley rats. Anesthesiology 1995; 83: 1220-32.

9. Gonsowski CT, Laster MJ, Eger EI II, et al. Toxicity of compound A in rats: effect of a 3-hour administration. Anesthesiology 1994; 80: 556-65.

10. Gonsowski CT, Laster MJ, Eger EI II, et al. Toxicity of compound A in rats. Effect of increasing duration of administration. Anesthesiology 1994; 80: 566-73.

11. Liu SJ, Li Y, Sun B, et al. A comparison between vital capacity induction and tidal breathing induction techniques for the induction of anesthesia and compound A production. Chin Med J (Engl). 2010; 123: 2336-40.

12. Fang ZX, Kandel L, Laster MJ, et al. Factors affecting production of compound A from the interaction of sevoflurane with Baralyme and Soda lime. Anesth Analg. 1996; 82: 779-81.

13. Laster M, Roth P, Eger EI 2nd. Fires from the interaction of anesthetics with desiccated absorbent. Anesth Analg. 2004; 99: 769-74.

14. Yao YT, Li LH, Chen L, et al. Sevoflurane postconditioning protects isolated rat hearts against ischemia-reperfusion injury: the role of radical oxygen species, extracellular signal-related kinases $1 / 2$ and mitochondrial permeability transition pore. Mol Biol Rep. 2010; 37(5): 2439-46.

15. Li H, Wang JK, Zeng YM, et al. Sevoflurane post-conditioning protects against myocardial reperfusion injury by activation of phosphatidylinositol- 3-kinase signal transduction. Clin Exp Pharmacol Physiol. 2008; 35: 1043-51.

16. Yao YT, Fang NX, Shi CX and Li LH. Sevoflurane postconditioning protects isolated rat hearts against ischemia-reperfusion injury. Chin Med J (Engl). 2010; 123(10): 1320-8.

17. Eger EI II, Koblin DD, Bowland T, et al. Nephrotoxicity of sevoflurane vs. desflurane anesthesia in volunteers. Anesth Analg 1997; 84:160-8.

18. W Funk, M Gruber, K Wild and J Hobbhahn. Dry soda lime markedly degrades sevoflurane during simulated inhalation induction. $\mathrm{Br} \mathrm{J}$ Anaesth. 1999; 82: 193-8.

19. Baker CE and Smith I. Sevoflurane: a comparison between vital capacity and tidal breathing techniques for the induction of anaesthesia and laryngeal mask airway placement. Anaesthesia 1999; 54: 841-4.

20. Hall JE, Stewart JIM and Harmer M. Single-breath inhalation induction of sevoflurane anaesthesia with and without nitrous oxide: a feasibility study in adults and comparison with an intravenous bolus of propofol. Anaesthesia 1997; 52: 410-5.

21. Ruffle JM, Snider MT, Rosenberger JL, et al. Rapid induction of halothane anaesthesia in man. Br J Anaesth. 1985; 57: 607-11.

22. Behne M, Wilke HJ, Harder S. Clinical pharmacokinetics of sevoflurane. Clin Pharmacokinet. 1999; 36: 13-26.

23. Moriwaki G, Bito H, Ikeda K. Partly exhausted soda lime or soda lime with water added, inhibits the increase in compound A concentration in the circle system during low-flow sevoflurane anaesthesia. Br J Anaesth. 1997; 79: 782-6.

24. Bito H, Ikeuchi $\mathrm{Y}$, Ikeda K. Effects of the water content of soda lime on compound A concentration in the anesthesia circuit in sevoflurane anesthesia. Anesthesiology 1998; 88: 66-71.

25. Cunningham DD, Huang S, Werster J, et al. Sevoflurane degradation to compound A in anaesthesia breathing systems. $\mathrm{Br} J$ Anaesth.1996;77:537-43.

26. Osafumi Yuge. Renal toxicity of compound A with sevoflurane anesthesia: The benefits of sevoflurane appear to outweigh the risks. J Anesth. 1997;11:1-2.

27. Kharasch ED, Thorning D, Garton K, et al. Role of renal cysteine conjugate beta-lyase in the mechanism of compound A nephrotoxicity in rats. Anesthesiology. 1997;86:160-71.

28. Kharasch ED, Jubert C, Spracklin DK, et al. Dose-dependent metabolism of fluoromethyl-2,2-difluoro-1-(trifluoromethyl) vinyl ether (compound A), an anesthetic degradation product, to mercapturic acids and 3,3,3-trifluoro-2-(fluoromethoxy) propanoic acid in rats. Toxicol Appl Pharmacol. 1999; 160:49-59. 